\title{
Modeling Presenilin-Dependent Familial Alzheimer's Disease: Emphasis on Presenilin Substrate-Mediated Signaling and Synaptic Function
}

\author{
Angèle T. Parent ${ }^{1}$ and Gopal Thinakaran ${ }^{1,2}$ \\ ${ }^{1}$ Department of Neurobiology, The University of Chicago, 924 East 57th Street, Chicago, IL 60637, USA \\ ${ }^{2}$ Department of Neurology, The University of Chicago, 924 East 57th Street, Chicago, IL 60637, USA
}

Correspondence should be addressed to Angèle T. Parent, aparent@uchicago.edu and Gopal Thinakaran, gopal@uchicago.edu

Received 15 April 2010; Accepted 17 June 2010

Academic Editor: Gemma Casadesus

Copyright (C) 2010 A. T. Parent and G. Thinakaran. This is an open access article distributed under the Creative Commons Attribution License, which permits unrestricted use, distribution, and reproduction in any medium, provided the original work is properly cited.

\begin{abstract}
Mutations in PSEN genes, which encode presenilin proteins, cause familial early-onset Alzheimer's disease (AD). Transgenic mouse models based on coexpression of familial AD-associated presenilin and amyloid precursor protein variants successfully mimic characteristic pathological features of $\mathrm{AD}$, including plaque formation, synaptic dysfunction, and loss of memory. Presenilins function as the catalytic subunit of $\gamma$-secretase, the enzyme that catalyzes intramembraneous proteolysis of amyloid precursor protein to release $\beta$-amyloid peptides. Familial AD-associated mutations in presenilins alter the site of $\gamma$-secretase cleavage in a manner that increases the generation of longer and highly fibrillogenic $\beta$-amyloid peptides. In addition to amyloid precursor protein, $\gamma$-secretase catalyzes intramembrane proteolysis of many other substrates known to be important for synaptic function. This paper focuses on how various animal models have enabled us to elucidate the physiological importance of diverse $\gamma$-secretase substrates, including amyloid precursor protein and discusses their roles in the context of cellular signaling and synaptic function.
\end{abstract}

\section{Introduction}

Mutations in PSEN1 and PSEN2 genes, which encode polytopic proteins termed presenilin 1 (PS1) and presenilin 2 (PS2), respectively, cause autosomal dominant early-onset familial Alzheimer's disease (FAD) [1]. Both PS1 and PS2 proteins (PS) share about 63\% homology with the highest similarity in the transmembrane domains where most of the FAD-linked mutations are found $[2,3]$. Since the first report of mutation in the PSEN1 on chromosome 14, about 170 mutations have been identified, making mutations in PSEN1 the most common cause of autosomal dominant early-onset $\mathrm{AD}$ [4]. In the case of PSEN2, 18 mutations have been reported so far, although not all have been confirmed to be pathogenic $[2,5]$. As a probable explanation for the disparity between the two genes, defects in PSEN2 function may be offset by the normal function of its homolog PSEN1. In support of this view, PSEN2 null mice do not exhibit the phenotypic and functional defects seen in mice lacking PSEN1 gene. PSEN1 knockout $(\mathrm{KO})$ mice are lethal, and disruption of PSEN2 and PSEN1 genes causes earlier embryonic lethality compared to PSEN1 KO [6-10]. As supported by mouse model studies, it appears that PS1 contributes largely to total $\beta$-amyloid $(\mathrm{A} \beta)$ production in the brain $[11,12]$.

PS is the catalytic subunit of $\gamma$-secretase, the enzyme responsible for intramembraneous cleavage of amyloid precursor protein (APP) to generate peptides. FAD-linked PS variants enhance the production of highly fibrillogenic $\mathrm{A} \beta 42$ peptides that are deposited early in the brains of patients with $\mathrm{AD}$ [13]. PS is ubiquitously expressed in the nervous system and peripheral tissue and found localized in secretory and endocytic organelles in all cell types, as well as synaptic structures in neurons $[14,15]$. As predicted from its broad pattern of expression, PS's function extends far beyond processing of APP and the pathogenesis of AD. For example, PS's catalytic function is required for intramembraneous $\gamma$-secretase cleavage of Notch receptors, which releases the Notch intracellular 
domain (NICD). Nuclear signaling mediated by NICD is essential during mammalian development; mice with ablated PSEN1 alleles die in late embryogenesis and exhibit phenotypes reminiscent of mice lacking Notch 1 [6, 7]. Thus, PS-dependent activation of Notch signaling is essential for early development. Transgenic expression of FAD-linked mutant PS1 fully rescues the developmental phenotypes in mice with PSEN1 deficiency $[16,17]$, supporting the notion that FAD-linked PS1 variants are functional, but acquired deleterious properties that have profound pathophysiological consequences. Candidate approaches and proteomic studies have identified a wide spectrum of type I membrane proteins that undergo $\gamma$-secretase cleavage, including Notch ligands, Deleted in Colorectal Cancer (DCC), and cadherins (reviewed in $[13,18-21]$ ). Uniformly these substrates all undergo an ectodomain shedding by $\alpha$-secretases, which in many cases is triggered by the binding of extracellular ligands. Interestingly, several noncatalytic $\gamma$-secretaseindependent functions have been assigned to PS, such as its role in regulating intracellular calcium homeostasis (reviewed in [22]).

Synapses are continuously reconfigured, both structurally and functionally, during embryonic development and throughout adult life, forming the basis for learning and memory $[23,24]$. Neuronal inability to exhibit such plastic changes has been proposed to be a root cause for various psychiatric and neurodegenerative disorders such as $\mathrm{AD}$ $[23,25,26]$. Not surprisingly, the duration and severity of cognitive impairments in $\mathrm{AD}$ patients closely parallels the extent of synaptic loss, leading to the notion that synaptic dysfunction is a critical element in the pathophysiology of AD [27]. Notably, memory and cognitive decline observed in $\mathrm{AD}$ patients correlate better with the synaptic pathology than either $A \beta$ plaque load or tangle density, and synapse loss appears to precede neuronal degeneration. Details on how synaptic organization is altered in $\mathrm{AD}$ patients are beginning to emerge. Findings from several laboratories suggesting that A $\beta$ might play a critical role in synaptic dysfunction have added significant information to the traditional amyloid cascade hypothesis of $\mathrm{AD}[28,29]$. A $\beta$ can affect synaptic transmission [30-33], synaptic protein localization [34], AMPA and NMDA receptor trafficking $[35,36]$, and spine formation [35, 37-39].

FAD-linked mutations in PS1 were originally thought to enhance the production of $A \beta 42$ peptides by a gainof-function mechanism. However, it is becoming clear that FAD-linked PS1 variants also exhibit partial-loss-ofenzymatic-function observed as diminution of $A \beta 40$ peptide production and defects in the extent of processing certain other transmembrane substrates (reviewed in $[40,41]$ ). For example, FAD-linked PS1 mutations are thought to attenuate $\gamma$-secretase processing and generate reduced levels of the intracellular domains of APP, Notch, N-cadherin, EphB2, and EphA4 [42-45]. Taken together, it is plausible that FAD-linked mutations in PS1 exert pathophysiological effects on the synapses by elevating $A \beta 42$ levels and by $A \beta-$ independent mechanisms involving altered processing of $\gamma$ secretase substrates involved in synaptic function. This paper discusses findings from various animal models that reveal the role of PS and FAD-linked PS mutations in synapse formation and function.

\section{PS Animal Models}

Several mouse models (reviewed in [46]; see http://www .alzforum.org/res/com/tra/) and a few rat models [47-50] have been developed in order to recapitulate the main pathological features of $\mathrm{AD}$ and elucidate the mechanisms by which FAD-linked PS mutations contribute to AD pathogenesis. A variety of mouse models have been characterized such as mice expressing FAD-linked PS variants harboring point mutations or deletion mutation $[51,52]$, and FADlinked PSEN1 knock-in (KI) [M146V variant [53], I213T variant [54] and P264L variant [55]], and $\Delta \mathrm{E} 10$ loop deletion KI [56]. These FAD-PS1 single transgenic or KI mouse models do not exhibit significant $A \beta$ deposition in the brain. Therefore, the phenotypes described in these FAD-PS1 single transgenic mice are not due to classical $\mathrm{A} \beta$ pathology. In an attempt to reproduce more closely the human $\mathrm{AD}$ pathology, PSEN1 KI coexpressing APP "Swedish" mutant and hyperphosphorylated tau mutants have been made [57].

In order to study the physiological function of PS, KO models of PSEN1 and PSEN2 [6-10], PSEN1 conditional KO [58-60], as well as double PSEN1 and PSEN2 conditional $\mathrm{KO}$ [61] mice have also been created. In order to examine amyloid pathology, transgenic mice expressing APP mutants in a PS null background have been developed; such as PSEN1 conditional KO coexpressing APP V717I variant [60] and APP V717F variant [62]. In these models, $A \beta$ deposition is attenuated by the lack of PS1 expression and consequent loss of $\gamma$-secretase activity.

Besides their utility in examining proteolytic processing of APP into $A \beta 40$ and $A \beta 42$ peptides in vivo and phenocopying pathological hallmarks of $\mathrm{AD}$ (amyloid deposition and tau phosphorylation), these models have been extensively used to examine changes in synaptic transmission, synaptic plasticity, and associated signaling. In addition, several groups have generated Drosophila models (reviewed in [63]), and Caenorhabditis elegans models (reviewed in [64]) expressing human PS1 or PS2 bearing FAD-linked mutations, in an effort to understand mechanistic contribution of $\mathrm{PS}$ to AD pathology and neuronal dysfunction.

\section{PS and Cellular Substrates of Memory}

Synaptic transmission and long-term potentiation (LTP) contribute to several forms of memory storage. Using slice preparations from transgenic mice, we and others have demonstrated that expression of FAD-linked PS1 does not alter basal synaptic transmission, but leads to higher degree of LTP induction in the hippocampus ( [57, 65-69] reviewed in [14]). However, one group has reported impairment of synaptic transmission associated with an increase of pairedpulse facilitation, an index of presynaptic release, in neurons of 6 month-old PSEN1 M146V KI mice [57]. LTP induction by high-frequency stimulation in hippocampal CA1 area was also enlarged in this animal model [57]. Interestingly, in PSEN1 M146V KI animal model, LTP induced by carbachol 
(a muscarinic agonist) was reduced in CA1 hippocampal area, suggesting that FAD-linked PS1 variant might interfere with cholinergic cellular cascades as well [70]. The KI mouse models allow us to examine the functional properties of molecules associated with pathology when they are expressed at endogenous levels without any alteration in their spatial or temporal pattern of expression. Therefore, KI animal models give us the opportunity to rule out pathophysiological consequences (such as protein misfolding) associated with aberrant overexpression of proteins associated with human genetic disorders.

Interestingly, it has been described that the lack of PS function or overexpression of PS1 mutant was also associated with changes in presynaptic function. We have observed an increase of spontaneous miniature excitatory postsynaptic current in cortical neurons isolated from PSEN1 KO mice [71], while others have reported that expression of mutant PS1 in cultured hippocampal neurons depresses synaptic transmission by reducing the number of synapses [72]. Another group has also observed that PS1 deficiency increases synaptic release and affects the number and docking of synaptic vesicles [69]. It was also shown that basal transmitter release was increased at the neuromuscular junction in Drosophila lacking PS expression [73]. However, even though basal synaptic transmission seems to be intensified in this later model, synaptic strength and plasticity were impaired after posttetanic potentiation [73]. As a likely consequence, associative learning ability was also impaired. In parallel, it has been reported that LTP induction declines more rapidly in CA1 hippocampal area of mice with only one allele of PSEN1 [74]. In agreement with these observations, it has been recently found that a CA3dependent presynaptic form of LTP in the hippocampus was attenuated in double PSEN1 and PSEN2 conditional KO mice [75]. Intriguingly, single PSEN1 conditional KO mice do not show major changes in brain plasticity, suggesting that expression of PS2 might be sufficient to overcome the 60 $80 \%$ loss of PS1 in the forebrain of these animals [59].

What can we learn from these animal models? First of all, it becomes apparent from these studies that PS is an essential element for the normal synapse function. Second, it becomes evident that PS dosage is a critical component for PS-dependent cellular function(s). Indeed, PS1 expression is developmentally regulated in rodent brain, reaching a peak of expression during the critical period of synaptogenesis between postnatal days 7 to 14 [76]. Accordingly, we can stipulate that PS-dependent substrates expressed during embryogenesis or early in development may significantly contribute to synaptic physiology. In this regard, it also remains to be established whether differences in PS-dependent proteolysis of developmentally regulated molecules might underlie changes in synaptic function later on in life. A well-known example is a condition where stress-induced early life biochemical events influence life-span changes in cognitive function and $\mathrm{AD}$-associated abnormalities [77]. Accordingly, it has been proposed that age-related decline in cortical cholinergic function in $\mathrm{AD}$ patients might have developmental origins [78]. Finally, it has also been speculated that PS-dependent modulation of signaling pathways that are important in development may contribute to the neurodegenerative process [79]. Taken together, studies from various laboratories suggest that PS is specifically involved in cellular component(s) necessary for synaptic transmission and plasticity, and that FAD-linked mutations in PS1 may disrupt the normal cascade of synaptic events.

\section{PS and Synapse Formation}

A distinct feature of the nervous system is the intricate network of synaptic connections among neurons. The changes in the strength and efficacy of existing synapses, as well as remodeling of connectivity through the loss and gain of synapses in the neuronal network, are believed to be the basis of learning and memory in the brain. Interestingly, LTP has been associated with the increase in spine formation and spine head growth, whereas long-term depression (LTD) has been associated with spine shrinkage and retraction [80]. The morphology of dendritic spines is known to change in response to several factors including learning, age, hormones, and disease conditions [81]. In addition to their morphological plasticity, spine-like protrusions also display rapid motility, changing shape and size in a matter of seconds to minutes. This morphological plasticity suggests that longterm memory might be encoded by alterations in spiny structures and associated synaptic contacts [82]. Collectively, these events are critically important in synaptogenesis, in modulating of existing synapses, as well as in long-term synaptic plasticity $[83,84]$. It has been reported that $A \beta$ is closely associated with a decrease of spine formation and motility $[35,37,85]$. Overproduction of $\mathrm{A} \beta$ in PS mutant transgenic mice coexpressing the "Swedish" APP mutant causes age-associated decrease of synaptic excitability [57, $86,87]$ and spine collapse $[38,88]$. However, it has also been reported that acute $A \beta$ application (less than $4 \mathrm{~h}$ ) was associated with an increase of filopodia and growth cones in hippocampal cultures [89]. In support of this idea, it was shown that application of low levels of $A \beta$ is associated with an increase of LTP, whereas higher concentration of $\mathrm{A} \beta$ reduced synaptic potentiation [32, 90]. Collectively, these observations suggest that $\mathrm{A} \beta$ might have dual roles on synapse formation. Conflicting results have also been observed in regard to spine morphology in neurons lacking PS expression. Treatment with Compound E, a $\gamma$-secretase inhibitor $(10 \mathrm{nM} ; 24 \mathrm{~h})$, produced an increase of spine-like protrusions in isolated neurons $[71,91]$; whereas the density of spines was found to be decreased upon prolonged treatment with the same inhibitor (50 nM; seven days) [45]. In addition, neurons lacking both PS1 and PS2 expression have marked diminution in spine density [45]. To further support the effect of $\gamma$-secretase inhibition on dendritic spines, recent in vivo study showed that $\gamma$-secretase inhibitor treatment in wild-type mice significantly reduced the number of spine density in somatosensory cortex, while $\gamma$-secretase inhibitor treated APP null mice did not exhibit any effect [92]. These findings suggest that APP-dependent mechanism may underlie the PS-dependent morphological changes observed. The apparent discrepancy between inhibitor treatment and 
loss of PS expression on spine density may be also due to differential effects of inhibitors that target mainly $\gamma$ secretase and genetic inactivation of PS that results in reduced $\gamma$-secretase-dependent and -independent function. All together, these observations support the idea that PS gene dosage and the level of expression may differentially influence synaptic morphology.

Although the molecular mechanisms that underlie these morphological changes are not completely understood, emerging evidence supports at least two important signaling pathways that have been linked to dendrite spine formation and AD etiology: (1) cAMP-dependent activation of PKA has been shown to be critical for the maintenance of the late phase of LTP, and downstream phosphorylation of CREB has been linked to formation of new spines [93]. Interestingly, it has been shown that $\mathrm{A} \beta$ inhibits PKA/CREB pathway [94], (2) the Rho family of small GTPases, well-known regulators of the actin cytoskeleton, has profound influence on spine formation. Among the members of this family Rac1, Cdc42, Rnd1, and Ras promote spine formation and growth, whereas Rap and RhoA induce shrinkage and loss of spines $[80,95]$. p21-activated kinase (PAK) is a downstream signaling effector of the Rho/Rac family of small GTPases and has been shown to be associated to spine formation and memory consolidation [96]. A role of PAK in cognitive deficits of $\mathrm{AD}$ has also been reported [97].

A recent paper by Shuai and colleagues [98] suggests that the act of forgetting might also be linked to activation of the Rac pathway, using a simplistic model of olfactory learning in the fruit fly Drosophila. With the help of genetic manipulation, they were able to distinguish changes in Rac activity during passive memory decay, interference learning, and reversal learning, which are three different forms of forgetting events. In Drosophila olfactory memory model, it appears that cAMP/PKA and Rac/PAK-dependent memory acquisition and forgetting events are independent, as suggested by this group and others $[98,99]$. In a more complex system, as it has been proposed in the mammals, it seems that memory consolidation might mechanistically require both pathways $[96,100,101]$. As demonstrated by several groups, Rac signaling cascade in the brain is directly linked to an increase of spine formation through subsequent activation of PAK leading to F-actin polymerization and changes in membrane morphology. Besides the known involvement of cAMP/PKA/CREB activation cascade, Rac/PAK-dependent cellular events also appear to be intimately associated with the process of memory consolidation, at least in rodents.

It is very exciting to think that perhaps similar cellular pathways as the one described above may be relevant to human disorders associated with memory dysfunction. One of the known hallmarks of $\mathrm{AD}$ is that patients do forget recent events, therefore, they are unable to consolidate their new memory. In our lab, we have shown that the lack of PS function or expression in cortical neurons produced an increase of steady-state levels of CREB and Rac/PAK cascade activation, which was also associated with an increase of spine-like protrusions [91]. Even though our study shows increase of phosphorylated CREB especially in dendritic area, transcriptional CREB activity was not directly determined in this experiment. More recently, Shen and collaborators have shown that CREB transcription was indeed reduced in PS deficient neuron through PSindependent mechanism [102]. Are these signaling events meaningful in the context of AD? Perhaps. As discussed above, recent studies support the idea that FAD-linked mutations in PS1 might cause a partial loss of function $[40,41]$. It still remains to be determined whether Rac/PAK signaling is altered in neurons expressing FAD-linked PS1 variants. If this is the case, one might want to consider the possibility that changes in cAMP/PKA/CREB or Rac/PAK signaling in neurons might represent some of the earliest cellular dysfunctions that are relevant to synapse elimination and associated cognitive decline in $\mathrm{AD}$.

\section{PS-Dependent Substrate Signaling}

$\gamma$-secretase-dependent PS function mediates transmembrane proteolysis of several substrates including APP, N- and E-cadherins, $\gamma$-protocadherin, CD44, DCC, ephrin/Eph receptors, leukocyte-common antigen related, nectin- $1 \alpha$, and syndecan (reviewed in $[18,20,21]$ ). Many of these substrates function as cell-adhesion molecules or cell surface receptors and are known for their diverse functions during development and are involved in axon guidance, neuronal outgrowth and synaptogenesis [103-113]. In addition, these molecules are also well known to be coupled to diverse intracellular signaling pathways $[20,44,45,108-110,114-$ 118]. It has been proposed that APP can affect synaptic function by its dual roles via its cell adhesive properties or through its putative receptor-like intracellular signaling components [112, 116, 117]. Indeed, it has been shown that accumulation of the APP intracellular domain can mediate a phosphoinositide-dependant calcium signaling [119]. Several other substrates of $\gamma$-secretase are also coupled with intracellular signaling events that can potentially influence synaptic function. For example, Eph receptors and $\mathrm{N}$-cadherin are known to be coupled to Rac and CREB signaling, respectively $[45,115,117,120,121]$. Lack of EphB expression or kinase-defective EphB is associated with a reduction in glutamatergic synapses and abnormal spine development [120-122].

It has also been shown that three substrates of PS, namely ErbB4, $\gamma$-protocadherin, and leukocyte-common antigen related, are associated with PSD-95 clustering at the synapse $[123,124]$ and AMPA receptor function [125]. Consistent with these findings, we have previously reported that the lack of PS function increases axodendritic contacts, which was accompanied by increases of PSD-95 clusters, spine-like protrusions, and AMPA receptors-mediated synaptic transmission [71, 91]. Moreover, PS1 KO neurons and Wt neurons treated with $\gamma$-secretase inhibitors exhibited increases in the extent of cAMP/PKA activation [71, 91]. cAMP/PKA signaling plays a critical role in regulating short and longterm synaptic physiology [126]. It has been demonstrated that stimulus-induced activation of PKA pathway can also affect the synaptic morphology; therefore, it can indirectly affect basal synaptic transmission [127]. Thus, there exists a close relationship between increased phosphorylation of 


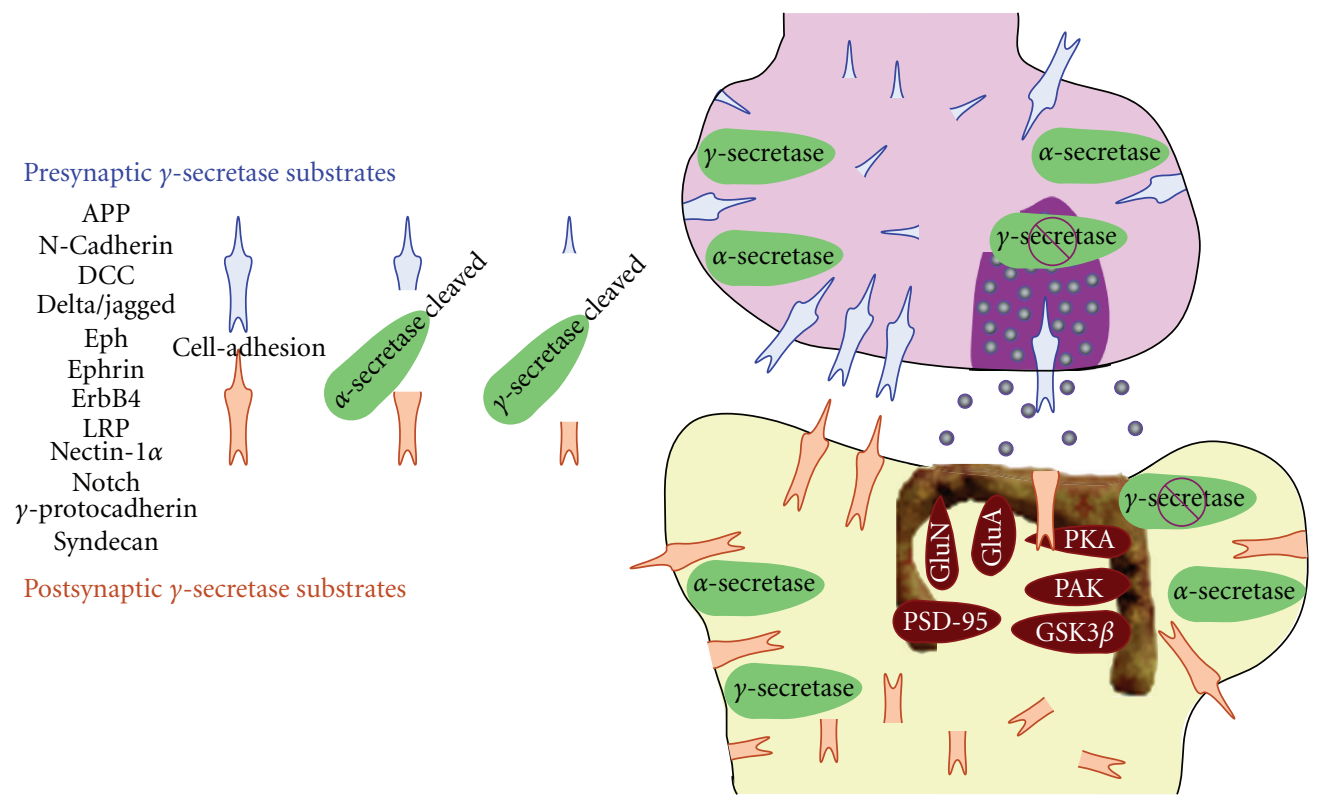

Signaling platform
- Signaling and interacting molecules
- Neurotransmitter

Figure 1: Schematic representation of PS-dependent processing of substrates and their role in synaptic function. Several $\gamma$-secretase substrates are located at the synapse where they influence the function of other synaptic proteins. Lack of $\gamma$-secretase-dependent cleavage of substrates could perturb presynaptic release and postsynaptic function of glutamate receptor-mediated events (NMDA-GluN and AMPAGluA receptors). Synaptic contact could also be modulated through cell-adhesion properties of several $\gamma$-secretase substrates. Inefficient processing of these substrates will lead to sustained activation of signaling cascades capable of altering the postsynaptic morphology. How FAD-linked mutations in PS influence these processes and contribute to the disease progression has not been fully understood.

PKA substrates and enhanced synaptic transmission in neurons lacking PS function $[71,91]$.

Signaling downstream of DCC, the netrin receptor [105], is also modulated by $\gamma$-secretase activity [71]. Upon binding of the ligand netrin, DCC undergoes metalloproteasedependent ectocomain shedding [128], which generates a membrane-tethered DCC C-terminal fragment (CTF) derivative, consisting of the transmembrane segment and the intracellular domain. DCC CTF undergoes intramembraneous proteolysis by $\gamma$-secretase, and accumulation of DCC CTF in neuroblastoma cells treated with $\gamma$-secretase inhibitors stimulates neurite outgrowth $[71,129] . \gamma$-secretase processing of DCC attenuates cAMP-dependent signaling cascades associated with DCC CTF [71]. In this case, it is clear that $\gamma$-secretase terminates intracellular signaling associated with DCC. However, it remains to be determined if $\gamma$-secretase cleavage of other substrates would significantly impact cellular functions, especially pertaining to synaptic process, through termination of receptor-mediated signaling events (see our proposed model in Figure 1).

More recently, it was found that EphA4 undergoes PS-dependent endoproteolytic process, and EphA4 CTF accumulates following inhibition of $\gamma$-secretase activity or in cells lacking PS expression [45]. Accumulation of EphA4
CTF was found tightly linked to an increase of spine-like protrusions in hippocampal cultures. Overexpression of an inactive Rac form abolished the enhancement of dendritic spines in neurons and lamellipodia formation in NIH3T3 cell lines. In addition, this study showed that overexpression of membrane-tethered EphA4 intracellular domain was also associated with an increase of lamellipodia formation in NIH3T3 cell lines. All together, these results suggest that enhanced accumulation of EphA4 intracellular domain may induce Rac-dependent signaling events that regulate cell morphology.

It is clear that loss of intramembraneous proteolysis of $\gamma$-secretase substrates leads to the accumulation of their membrane-tethered cytosolic domains. The CTFs of certain substrates might serve as membrane anchors to facilitate the recruitment of signaling proteins in a manner that enhances phosphorylation of downstream signaling substrates. One of the signalings that have been implicated with PS function is GSK3 $\beta$ (reviewed in [130]). It is well established that PS1 can interact with the GSK3 $\beta / \beta$-catenin complex [131-133]. However, besides this direct physical interaction with PS1, it is known that GSK $3 \beta$ is a ligandreceptor signaling molecule downstream of the activation of phosphatidylinositol-3-kinase pathway (reviewed in [134]). 
Specifically, it has been shown that GSK3 $\beta$ signaling is important for axon specification and elongation during the establishment of neuronal polarity (review by [135]). In addition, it has been reported that decrease of GSK3 $\beta$ activity parallels LTP induction paradigms, whereas inhibition of phosphatidylinositol-3-kinase and subsequent activation of GSK3 $\beta$ lead to decrease of LTP ([136]; reviewed in [130, 137]). Decreased phosphorylation of GSK3 $\beta$ at the Ser 9 residue, indicative of an increase of GSK activity, was also observed in PS1-deficient neurons as well as in PS1 neurons carrying FAD-linked mutations [69, 138-141]. Alteration of phosphatidylinositol-3-kinase /Akt signaling cascade has been proposed to be the link between GSK $3 \beta$ activity and PS function $[138,140,142]$. Interestingly, increase of GSK3 $\beta$ activity also leads to hyperphosphorylation of tau protein, which underlies one of the known pathological hallmarks of $\mathrm{AD}$, namely the tangle formation (reviewed in [130]).

It has been proposed that membrane microdomains rich in cholesterol and sphingolipids, termed lipid rafts, might influence $\gamma$-secretase activity and processing of substrates (reviewed in [143]). Lipid rafts play an important role in the maintenance of synapses through dendritic spine formation and AMPA receptor function [144]. Raft-dependent mechanisms facilitate trafficking of receptors in and out of the synapse and regulate synapse function (reviewed in [145]). Lipid rafts are known to serve as membrane platforms that compartmentalize diverse receptor-mediated signaling. Indeed, it was found that critical regulation of signaling associated with ErbB4, DCC, and EphA4, three $\gamma$-secretase substrates, involves their recruitment into lipid raft microdomains $[45,146,147]$. Based on the differences in spatiotemporal distribution of $\gamma$-secretase complexes and substrates [148, 149], different PS-dependent substrates might be subjected to different level of proteolysis depending on their membrane microdomain distribution at a given time during embryonic development and in adult life.

\section{PS and Calcium Signaling}

Besides a direct interaction of $\gamma$-secretase substrates with intracellular phosphorylation cascades, one of the key features of PS function is its role in intracellular $\mathrm{Ca}^{2+}$ homeostasis (reviewed in $[22,150,151]) . \mathrm{Ca}^{2+}$ homeostasis is essential to maintain healthy cellular dynamics leading to proper physiological functions. Several studies have concluded that FAD-linked PS mutant expression in transfected cells and cultured neurons is associated with enhanced $\mathrm{Ca}^{2+}$ release from endoplasmic reticulum store. It has been reported that neurons generated from PSEN1 M146V KI mice exhibit an increase of $\mathrm{IP}_{3}$-evoked $\mathrm{Ca}^{2+}$ responses in brain slices as early as in one month old [152]. This $\mathrm{Ca}^{2+}$ dysregulation appears to be specific to intracellular endoplasmic reticulum store since it does not affect the voltage-gated $\mathrm{Ca}^{2+}$ entry. However, it has been shown that L-type $\mathrm{Ca}^{2+}$ channel may be involved after stress induction at the neuromuscular junction in drosophila larvae expressing FAD-linked PS1 mutant [153]. Accordingly, in this model system, the level of synaptic plasticity and memory paradigm was normal following heat shock stimulation or endoplasmic reticulum stress, but reduced after $24 \mathrm{~h}$ of stimulation recovery. These results suggest that mutation in PS might alter synaptic behavior following recovery of stress conditions. It has been also proposed that PS might serve as a passive $\mathrm{Ca}^{2+}$ leak channel in the endoplasmic reticulum and FAD-linked PS variants might fail to exhibit this property [154]. Using reconstituted planar lipid bilayers, Tu and collaborators demonstrated that PS by itself could form low-conductance divalent ion channels, which was not the case in several mutated forms of PS. It remains to be determined if results from these experimental conditions are applicable to in vivo situations that are relevant to the disease state.

More recently, Stutzmann and collaborators have established that the ryanodine receptor-evoked $\mathrm{Ca}^{2+}$ release (especially through RyR2 isoform) was increased in CA1 hippocampal slices of PSEN1 M146V KI mice coexpressing Swedish APP and hyperphosphorylated tau mutants [155]. As a consequence, they observed an aberrant increase of ryanodine-dependent presynaptic neurotransmission, along with increases of long-term synaptic plasticity. Conversely, Shen and collaborators have observed a decrease of ryanodine-dependent presynaptic release in hippocampal neurons of PS-deficient mice [75]. All together, Stutzmann group concluded from their study that significant $\mathrm{Ca}^{2+}$ alterations are present at an early age even though $\mathrm{Ca}^{2+}$ homeostasis appears to be maintained. Compensatory mechanisms seem likely to take place in order to maintain normal synaptic function in early age. However, these subtle $\mathrm{Ca}^{2+}$ mediated alterations may have profound impact later on that can affect synaptic and cognitive functions in disease states.

\section{Conclusions}

Production and deposition of $\mathrm{A} \beta$ peptides clearly have central role in AD pathogenesis. However, it is becoming clear that FAD-linked mutations in PS proteins affect diverse physiological processes in addition to promoting the production of highly fibrillogenic $A \beta 42$ peptides. The identification and characterization of $\gamma$-secretase substrates and the mechanistic details on the successive cleavage of substrates by the $\gamma$-secretase have enhanced our understanding of how partial loss-of-function associated with FAD-linked PS mutations can in fact lead to a gain of activities with reference to intracellular signaling associated with certain substrates such as DCC, ErbB4, and EphA4. At least in some cases, lack of $\gamma$-secretase processing leads to profound changes in synaptic structure and functions as a consequence of sustained intracellular signaling by substrate CTFs. As details begin to emerge on additional $\gamma$-secretase substrates, it will be possible to determine whether $\gamma$-secretase cleavage of neuronal receptors is indeed a regulatory step that modulates physiological signaling downstream of ligand binding and ectodomain shedding. Still, the major task is to establish whether or not altered signaling directly contributes to $\mathrm{AD}$ pathogenesis and/or AD-related synaptic dysfunction.

\section{Disclosure}

The authors declare no competing interest. 


\section{Acknowledgments}

Research in the author's laboratories is supported by the National Institutes of Health Grants (ATP: NS055223; GT: AG021495, and AG019070) and by grants from the Alzheimer's Association and American Health Assistance Foundation.

\section{References}

[1] R. E. Tanzi and L. Bertram, "New frontiers in Alzheimer's disease genetics," Neuron, vol. 32, no. 2, pp. 181-184, 2001.

[2] E. Levy-Lahad, W. Wasco, P. Poorkaj et al., "Candidate gene for the chromosome 1 familial Alzheimer's disease locus," Science, vol. 269, no. 5226, pp. 973-977, 1995.

[3] L. Bertram and R. E. Tanzi, "Thirty years of Alzheimer's disease genetics: the implications of systematic meta-analyses," Nature Reviews Neuroscience, vol. 9, no. 10, pp. 768-778, 2008.

[4] R. Sherrington, E. I. Rogaev, Y. Liang et al., "Cloning of a gene bearing missense mutations in early-onset familial Alzheimer's disease," Nature, vol. 375, no. 6534, pp. 754-760, 1995.

[5] E. I. Rogaev, R. Sherrington, E. A. Rogaeva et al., "Familial Alzheimer's disease in kindreds with missense mutations in a gene on chromosome 1 related to the Alzheimer's disease type 3 gene," Nature, vol. 376, no. 6543, pp. 775-778, 1995.

[6] P. C. Wong, H. Zheng, H. Chen et al., "Presenilin 1 is required for Notch 1 and Dll1 expression in the paraxial mesoderm," Nature, vol. 387, no. 6630, pp. 288-292, 1997.

[7] J. Shen, R. T. Bronson, D. F. Chen, W. Xia, D. J. Selkoe, and S. Tonegawa, "Skeletal and CNS defects in Presenilin-1deficient mice," Cell, vol. 89, no. 4, pp. 629-639, 1997.

[8] D. B. Donoviel, A.-K. Hadjantonakis, M. Ikeda, H. Zheng, P. S. G. Hyslop, and A. Bernstein, "Mice lacking both presenilin genes exhibit early embryonic patterning defects," Genes and Development, vol. 13, no. 21, pp. 2801-2810, 1999.

[9] H. Steiner, K. Duff, A. Capell et al., "A loss of function mutation of presenilin-2 interferes with amyloid $\beta$ - peptide production and Notch signaling," The Journal of Biological Chemistry, vol. 274, no. 40, pp. 28669-28673, 1999.

[10] A. Herreman, D. Hartmann, W. Annaert et al., "Presenilin 2 deficiency causes a mild pulmonary phenotype and no changes in amyloid precursor protein processing but enhances the embryonic lethal phenotype of presenilin 1 deficiency," Proceedings of the National Academy of Sciences of the United States of America, vol. 96, no. 21, pp. 11872-11877, 1999.

[11] B. De Strooper, P. Saftig, K. Craessaerts et al., "Deficiency of presenilin-1 inhibits the normal cleavage of amyloid precursor protein," Nature, vol. 391, no. 6665, pp. 387-390, 1998.

[12] S. Naruse, G. Thinakaran, J.-J. Luo et al., "Effects of PS1 deficiency on membrane protein trafficking in neurons," Neuron, vol. 21, no. 5, pp. 1213-1221, 1998.

[13] S. S. Sisodia and P. H. St George-Hyslop, " $\gamma$-secretase, Notch, $\mathrm{A} \beta$ and Alzheimer's disease: where do the presenilins fit in?" Nature Reviews Neuroscience, vol. 3, no. 4, pp. 281-290, 2002.

[14] G. Thinakaran and A. T. Parent, "Identification of the role of presenilins beyond Alzheimer's disease," Pharmacological Research, vol. 50, no. 4, pp. 411-418, 2004.

[15] S. Frykman, J.-Y. Hur, J. Frånberg et al., "Synaptic and endosomal localization of active $\gamma$-secretase in rat brain," PLoS ONE, vol. 5, no. 1, Article ID e8948, pp. 1-10, 2010.
[16] J. A. Davis, S. Naruse, H. Chen et al., "An Alzheimer's diseaselinked PS1 variant rescues the developmental abnormalities of PS1-deficient embryos," Neuron, vol. 20, no. 3, pp. 603609, 1998.

[17] S. Qian, P. Jiang, X.-M. Guan et al., "Mutant human presenilin 1 protects presenilin 1 null mouse against embryonic lethality and elevates A $\beta 1-42 / 43$ expression," Neuron, vol. 20, no. 3, pp. 611-617, 1998.

[18] K. S. Vetrivel, Y.-W. Zhang, H. Xu, and G. Thinakaran, "Pathological and physiological functions of presenilins," Molecular Neurodegeneration, vol. 1, no. 1, article 4, 2006.

[19] R. Kopan and M. X. G. Ilagan, " $\gamma$-Secretase: proteasome of the membrane?" Nature Reviews Molecular Cell Biology, vol. 5, no. 6, pp. 499-504, 2004.

[20] A. L. Parks and D. Curtis, "Presenilin diversifies its portfolio," Trends in Genetics, vol. 23, no. 3, pp. 140-150, 2007.

[21] J. V. McCarthy, C. Twomey, and P. Wujek, "Presenilindependent regulated intramembrane proteolysis and $\gamma$ secretase activity," Cellular and Molecular Life Sciences, vol. 66, no. 9, pp. 1534-1555, 2009.

[22] G. Thinakaran and S. S. Sisodia, "Presenilins and Alzheimer disease: the calcium conspiracy," Nature Neuroscience, vol. 9, no. 11, pp. 1354-1355, 2006.

[23] C. L. Waites, A. M. Craig, and C. C. Garner, "Mechanisms of vertebrate synaptogenesis," Annual Review of Neuroscience, vol. 28, pp. 251-274, 2005.

[24] E. Bruel-Jungerman, S. Davis, and S. Laroche, "Brain plasticity mechanisms and memory: a party of four," Neuroscientist, vol. 13, no. 5, pp. 492-505, 2007.

[25] S. W. Scheff and D. A. Price, "Synaptic pathology in Alzheimer's disease: a review of ultrastructural studies," Neurobiology of Aging, vol. 24, no. 8, pp. 1029-1046, 2003.

[26] R. D. Terry, E. Masliah, D. P. Salmon et al., "Physical basis of cognitive alterations in Alzheimer's disease: synapse loss is the major correlate of cognitive impairment," Annals of Neurology, vol. 30, no. 4, pp. 572-580, 1991.

[27] D. J. Selkoe, "Alzheimer's disease is a synaptic failure," Science, vol. 298, no. 5594, pp. 789-791, 2002.

[28] R. E. Tanzi, "The synaptic A $\beta$ hypothesis of Alzheimer disease," Nature Neuroscience, vol. 8, no. 8, pp. 977-979, 2005.

[29] G. M. Shankar and D. M. Walsh, "Alzheimer's disease: synaptic dysfunction and A $\beta$," Molecular Neurodegeneration, vol. 4 , no. 1, article 48, 2009.

[30] F. Kamenetz, T. Tomita, H. Hsieh et al., "APP processing and synaptic function,” Neuron, vol. 37, no. 6, pp. 925-937, 2003.

[31] E. Abramov, I. Dolev, H. Fogel, G. D. Ciccotosto, E. Ruff, and I. Slutsky, "Amyloid- $\beta$ as a positive endogenous regulator of release probability at hippocampal synapses," Nature Neuroscience, vol. 12, no. 12, pp. 1567-1576, 2009.

[32] G. M. Shankar, S. Li, T. H. Mehta et al., "Amyloid- $\beta$ protein dimers isolated directly from Alzheimer's brains impair synaptic plasticity and memory," Nature Medicine, vol. 14, no. 8, pp. 837-842, 2008.

[33] S. Li, S. Hong, N. E. Shepardson, D. M. Walsh, G. M. Shankar, and D. Selkoe, "Soluble oligomers of amyloid beta protein facilitate hippocampal long-term depression by disrupting neuronal glutamate uptake," Neuron, vol. 62, no. 6, pp. 788801, 2009.

[34] C. G. Almeida, D. Tampellini, R. H. Takahashi et al., "Betaamyloid accumulation in APP mutant neurons reduces PSD95 and GluR1 in synapses," Neurobiology of Disease, vol. 20, no. 2, pp. 187-198, 2005. 
[35] H. Hsieh, J. Boehm, C. Sato et al., "AMPAR removal underlies A $\beta$-induced synaptic depression and dendritic spine loss," Neuron, vol. 52, no. 5, pp. 831-843, 2006.

[36] E. M. Snyder, Y. Nong, C. G. Almeida et al., "Regulation of NMDA receptor trafficking by amyloid- $\beta$," Nature Neuroscience, vol. 8, no. 8, pp. 1051-1058, 2005.

[37] B. R. Shrestha, O. V. Vitolo, P. Joshi, T. Lordkipanidze, M. Shelanski, and A. Dunaevsky, "Amyloid $\beta$ peptide adversely affects spine number and motility in hippocampal neurons," Molecular and Cellular Neuroscience, vol. 33, no. 3, pp. 274282, 2006.

[38] J. Tsai, J. Grutzendler, K. Duff, and W.-B. Gan, "Fibrillar amyloid deposition leads to local synaptic abnormalities and breakage of neuronal branches," Nature Neuroscience, vol. 7, no. 11, pp. 1181-1183, 2004.

[39] W. Wei, L. N. Nguyen, H. W. Kessels, H. Hagiwara, S. Sisodia, and R. Malinow, "Amyloid beta from axons and dendrites reduces local spine number and plasticity," Nature Neuroscience, vol. 13, no. 2, pp. 190-196, 2010.

[40] B. De Strooper, "Loss-of-function presenilin mutations in Alzheimer disease. Talking Point on the role of presenilin mutations in Alzheimer disease," EMBO Reports, vol. 8, no. 2, pp. 141-146, 2007.

[41] M. S. Wolfe, "When loss is gain: reduced presenilin proteolytic function leads to increased $A \beta 42 / \mathrm{A} \beta 40$. Talking point on the role of presenilin mutations in Alzheimer disease," EMBO Reports, vol. 8, no. 2, pp. 136-140, 2007.

[42] X. Cao and T. C. Südhof, "A transcriptivety active complex of APP with Fe65 and histone acetyltransferase Tip60," Science, vol. 293, no. 5527, pp. 115-120, 2001.

[43] T. Moehlmann, E. Winkler, X. Xia et al., "Presenilin-1 mutations of leucine 166 equally affect the generation of the Notch and APP intracellular domains independent of their effect on A $\beta 42$ production," Proceedings of the National Academy of Sciences of the United States of America, vol. 99, no. 12, pp. 8025-8030, 2002.

[44] C. Litterst, A. Georgakopoulos, J. Shioi et al., "Ligand binding and calcium influx induce distinct ectodomain $/ \gamma$ - secretaseprocessing pathways of EphB2 receptor," The Journal of Biological Chemistry, vol. 282, no. 22, pp. 16155-16163, 2007.

[45] E. Inoue, M. Deguchi-Tawarada, A. Togawa et al., "Synaptic activity prompts $\gamma$-secretase-mediated cleavage of EphA4 and dendritic spine formation," Journal of Cell Biology, vol. 185, no. 3, pp. 551-564, 2009.

[46] R. Radde, C. Duma, M. Goedert, and M. Jucker, "The value of incomplete mouse models of Alzheimer's disease," European Journal of Nuclear Medicine and Molecular Imaging, vol. 35, no. 1, supplement, pp. S70-S74, 2008.

[47] V. Echeverria, A. Ducatenzeiler, L. Alhonen et al., "Rat transgenic models with a phenotype of intracellular $A \beta$ accumulation in hippocampus and cortex," Journal of Alzheimer's Disease, vol. 6, no. 3, pp. 209-219, 2004.

[48] V. Echeverria, A. Ducatenzeiler, E. Dowd et al., "Altered mitogen-activated protein kinase signaling, tau hyperphosphorylation and mild spatial learning dysfunction in transgenic rats expressing the $\beta$-amyloid peptide intracellularly in hippocampal and cortical neurons," Neuroscience, vol. 129, no. 3, pp. 583-592, 2004.

[49] D. G. Flood, Y.-G. Lin, D. M. Lang et al., "A transgenic rat model of Alzheimer's disease with extracellular $\mathrm{A} \beta$ deposition," Neurobiology of Aging, vol. 30, no. 7, pp. 10781090, 2009.
[50] W. C. Leon, F. Canneva, V. Partridge, et al., "A novel transgenic rat model with a full Alzheimer's-like amyloid pathology displays pre-plaque intracellular amyloid-betaassociated cognitive impairment," Journal of Alzheimer's Disease, vol. 20, no. 1, pp. 113-126, 2010.

[51] D. R. Borchelt, G. Thinakaran, C. B. Eckman et al., "Familial Alzheimer's disease-linked presenilin I variants elevate a $\beta 1$ 42/1-40 ratio in vitro and in vivo," Neuron, vol. 17, no. 5, pp. 1005-1013, 1996.

[52] K. Duff, C. Eckman, C. Zehr et al., "Increased amyloid$\beta 42(43)$ in brains of mice expressing mutant presenilin 1," Nature, vol. 383, no. 6602, pp. 710-713, 1996.

[53] Q. Guo, W. Fu, B. L. Sopher et al., "Increased vulnerability of hippocampal neurons to excitotoxic necrosis in presenilin-1 mutant knock-in mice," Nature Medicine, vol. 5, no. 1, pp. 101-106, 1999.

[54] Y. Nakano, G. Kondoh, T. Kudo et al., "Accumulation of murine amyloid $\beta 42$ in a gene-dosage-dependent manner in PS1 'knock-in' mice," European Journal of Neuroscience, vol. 11, no. 7, pp. 2577-2581, 1999.

[55] R. Siman, A. G. Reaume, M. J. Savage et al., "Presenilin1 P264L knock-in mutation: differential effects on $\mathrm{A} \beta$ production, amyloid deposition, and neuronal vulnerability," Journal of Neuroscience, vol. 20, no. 23, pp. 8717-8726, 2000.

[56] Y. Deng, L. Tarassishin, V. Kallhoff et al., "Deletion of presenilin 1 hydrophilic loop sequence leads to impaired $\gamma$-secretase activity and exacerbated amyloid pathology," Journal of Neuroscience, vol. 26, no. 14, pp. 3845-3854, 2006.

[57] S. Oddo, A. Caccamo, J. D. Shepherd et al., "Triple-transgenic model of Alzheimer's Disease with plaques and tangles: intracellular A $\beta$ and synaptic dysfunction," Neuron, vol. 39, no. 3, pp. 409-421, 2003.

[58] H. Yu, C. A. Saura, S.-Y. Choi et al., "APP processing and synaptic plasticity in presenilin-1 conditional knockout mice," Neuron, vol. 31, no. 5, pp. 713-726, 2001.

[59] R. Feng, C. Rampon, Y.-P. Tang et al., "Deficient neurogenesis in forebrain-specific presenilin-1 knockout mice is associated with reduced clearance of hippocampal memory traces," Neuron, vol. 32, no. 5, pp. 911-926, 2001.

[60] I. Dewachter, D. Reversé, N. Caluwaerts et al., "Neuronal deficiency of presenilin 1 inhibits amyloid plaque formation and corrects hippocampal long-term potentiation but not a cognitive defect of amyloid precursor protein [v717i] transgenic mice," Journal of Neuroscience, vol. 22, no. 9, pp. 3445-3453, 2002.

[61] C. A. Saura, S.-Y. Choi, V. Beglopoulos et al., "Loss of presenilin function causes impairments of memory and synaptic plasticity followed by age-dependent neurodegeneration," Neuron, vol. 42, no. 1, pp. 23-36, 2004.

[62] C. A. Saura, G. Chen, S. Malkani et al., "Conditional inactivation of presenilin 1 prevents amyloid accumulation and temporarily rescues contextual and spatial working memory impairments in amyloid precursor protein transgenic mice," Journal of Neuroscience, vol. 25, no. 29, pp. 6755-6764, 2005.

[63] G. A. Seidner, Y. Ye, M. M. Faraday, W. G. Alvord, and M. E. Fortini, "Modeling clinically heterogeneous presenilin mutations with transgenic Drosophila," Current Biology, vol. 16, no. 10, pp. 1026-1033, 2006.

[64] A. Smialowska and R. Baumeister, "Presenilin function in Caenorhabditis elegans," Neurodegenerative Diseases, vol. 3, no. 4-5, pp. 227-232, 2006. 
[65] A. Parent, D. J. Linden, S. S. Sisodia, and D. R. Borchelt, "Synaptic transmission and hippocampal long-term potentiation in transgenic mice expressing FAD-linked presenilin 1," Neurobiology of Disease, vol. 6, no. 1, pp. 56-62, 1999.

[66] S. H. Zaman, A. Parent, A. Laskey et al., "Enhanced synaptic potentiation in transgenic mice expressing presenilin 1 familial Alzheimer's disease mutation is normalized with a benzodiazepine," Neurobiology of Disease, vol. 7, no. 1, pp. 54-63, 2000.

[67] P. A. Barrow, R. M. Empson, S. J. Gladwell et al., "Functional phenotype in transgenic mice expressing mutant human presenilin-1," Neurobiology of Disease, vol. 7, no. 2, pp. 119$126,2000$.

[68] I. Schneider, D. Reversé, I. Dewachter et al., "Mutant presenilins disturb neuronal calcium homeostasis in the brain of transgenic mice, decreasing the threshold for excitotoxicity and facilitating long-term potentiation," The Journal of Biological Chemistry, vol. 276, no. 15, pp. 11539-11544, 2001.

[69] I. Dewachter, L. Ris, S. Croes et al., "Modulation of synaptic plasticity and Tau phosphorylation by wild-type and mutant presenilin1," Neurobiology of Aging, vol. 29, no. 5, pp. 639652, 2008.

[70] Y. Wang, N. H. Greig, Q.-S. Yu, and M. P. Mattson, "Presenilin-1 mutation impairs cholinergic modulation of synaptic plasticity and suppresses NMDA currents in hippocampus slices," Neurobiology of Aging, vol. 30, no. 7, pp. 1061-1068, 2009.

[71] A. T. Parent, N. Y. Barnes, Y. Taniguchi, G. Thinakaran, and S. S. Sisodia, "Presenilin attenuates receptor-mediated signaling and synaptic function," Journal of Neuroscience, vol. 25, no. 6, pp. 1540-1549, 2005.

[72] C. Priller, I. Dewachter, N. Vassallo et al., "Mutant presenilin 1 alters synaptic transmission in cultured hippocampal neurons," The Journal of Biological Chemistry, vol. 282, no. 2, pp. 1119-1127, 2007.

[73] D. Knight, K. Iliadi, M. P. Charlton, H. L. Atwood, and G. L. Boulianne, "Presynaptic plasticity and associative learning are impaired in a Drosophila presenilin null mutant," Developmental Neurobiology, vol. 67, no. 12, pp. 1598-1613, 2007.

[74] R. A. Morton, F. M. Kuenzi, S. M. Fitzjohn et al., "Impairment in hippocampal long-term potentiation in mice underexpressing the Alzheimer's disease related gene presenilin-1," Neuroscience Letters, vol. 319, no. 1, pp. 37-40, 2002.

[75] C. Zhang, B. Wu, V. Beglopoulos et al., "Presenilins are essential for regulating neurotransmitter release," Nature, vol. 460, no. 7255, pp. 632-636, 2009.

[76] X.-X. Yan, T. Li, C. M. Rominger et al., "Binding sites of gamma-secretase inhibitors in rodent brain: distribution, postnatal development, and effect of deafferentation," Journal of Neuroscience, vol. 24, no. 12, pp. 2942-2952, 2004.

[77] B. S. McEwen, "Early life influences on life-long patterns of behavior and health," Mental Retardation and Developmental Disabilities Research Reviews, vol. 9, no. 3, pp. 149-154, 2003.

[78] M. Sarter and J. P. Bruno, "Developmental origins of the agerelated decline in cortical cholinergic function and associated cognitive abilities," Neurobiology of Aging, vol. 25, no. 9, pp. 1127-1139, 2004.

[79] E. H. Koo and R. Kopan, "Potential role of presenilinregulated signaling pathways in sporadic neurodegeneration," Nature Medicine, vol. 10, pp. S26-S33, 2004.

[80] T. Tada and M. Sheng, "Molecular mechanisms of dendritic spine morphogenesis," Current Opinion in Neurobiology, vol. 16, no. 1, pp. 95-101, 2006.
[81] K. E. Sorra and K. M. Harris, "Overview on the structure, composition, function, development, and plasticity of hippocampal dendritic spines," Hippocampus, vol. 10, no. 5, pp. 501-511, 2000.

[82] C. Lüscher, R. A. Nicoll, R. C. Malenka, and D. Muller, "Synaptic plasticity and dynamic modulation of the postsynaptic membrane," Nature Neuroscience, vol. 3, no. 6, pp. 545-550, 2000.

[83] R. Yuste and T. Bonhoeffer, "Morphological changes in dendritic spines associated with long-term synaptic plasticity," Annual Review of Neuroscience, vol. 24, pp. 1071-1089, 2001.

[84] T. Bonhoeffer and R. Yuste, "Spine motility: phenomenology, mechanisms, and function," Neuron, vol. 35, no. 6, pp. 10191027, 2002.

[85] G. M. Shankar, B. L. Bloodgood, M. Townsend, D. M. Walsh, D. J. Selkoe, and B. L. Sabatini, "Natural oligomers of the Alzheimer amyloid- $\beta$ protein induce reversible synapse loss by modulating an NMDA-type glutamate receptordependent signaling pathway," Journal of Neuroscience, vol. 27, no. 11, pp. 2866-2875, 2007.

[86] S. M. Fitzjohn, R. A. Morton, F. Kuenzi et al., "Agerelated impairment of synaptic transmission but normal potentiation in transgenic mice that overexpress the human APP695SWE mutant form of amyloid precursor protein," Journal of Neuroscience, vol. 21, no. 13, pp. 4691-4698, 2001.

[87] E. H. Chang, M. J. Savage, D. G. Flood et al., "AMPA receptor downscaling at the onset of Alzheimer's disease pathology in double knockin mice," Proceedings of the National Academy of Sciences of the United States of America, vol. 103, no. 9, pp. 3410-3415, 2006.

[88] T. L. Spires, M. Meyer-Luehmann, E. A. Stern et al., "Dendritic spine abnormalities in amyloid precursor protein transgenic mice demonstrated by gene transfer and intravital multiphoton microscopy," Journal of Neuroscience, vol. 25, no. 31, pp. 7278-7287, 2005.

[89] A. Mendoza-Naranjo, C. Gonzalez-Billault, and R. B. Maccioni, "A $\beta 1-42$ stimulates actin polymerization in hippocampal neurons through Racl and Cdc42 Rho GTPases," Journal of Cell Science, vol. 120, no. 2, pp. 279-288, 2007.

[90] D. Puzzo, L. Privitera, E. Leznik et al., "Picomolar amyloid$\beta$ positively modulates synaptic plasticity and memory in hippocampus," Journal of Neuroscience, vol. 28, no. 53, pp. 14537-14545, 2008.

[91] N. Y. Barnes, J. Shi, H. Yajima, G. Thinakaran, and A. T. Parent, "Steady-state increase of cAMP-response element binding protein, Rac, and PAK signaling in presenilindeficient neurons," Journal of Neurochemistry, vol. 104, no. 6, pp. 1637-1648, 2008.

[92] T. Bittner, M. Fuhrmann, S. Burgold et al., " $\gamma$-secretase inhibition reduces spine density in vivo via an amyloid precursor protein-dependent pathway," Journal of Neuroscience, vol. 29, no. 33, pp. 10405-10409, 2009.

[93] D. D. Murphy and M. Segal, "Morphological plasticity of dendritic spines in central neurons is mediated by activation of cAMP response element binding protein," Proceedings of the National Academy of Sciences of the United States of America, vol. 94, no. 4, pp. 1482-1487, 1997.

[94] O. V. Vitolo, A. Sant'Angelo, V. Costanzo, F. Battaglia, O. Arancio, and M. Shelanski, "Amyloid $\beta$-peptide inhibition of the PKA/CREB pathway and long-term potentiation: reversibility by drugs that enhance cAMP signaling," Proceedings of the National Academy of Sciences of the United States of America, vol. 99, no. 20, pp. 13217-13221, 2002. 
[95] M. Negishi and H. Katoh, "Rho family GTPases and dendrite plasticity," Neuroscientist, vol. 11, no. 3, pp. 187-191, 2005.

[96] M. L. Hayashi, S.-Y. Choi, B. S. Rao et al., "Altered cortical synaptic morphology and impaired memory consolidation in forebrain- specific dominant-negative PAK transgenic mice," Neuron, vol. 42, no. 5, pp. 773-787, 2004.

[97] L. Zhao, Q.-L. Ma, F. Calon et al., "Role of p21-activated kinase pathway defects in the cognitive deficits of Alzheimer disease," Nature Neuroscience, vol. 9, no. 2, pp. 234-242, 2006.

[98] Y. Shuai, B. Lu, Y. Hu, L. Wang, K. Sun, and Y. Zhong, "Forgetting is regulated through rac activity in Drosophila," Cell, vol. 140, no. 4, pp. 579-589, 2010.

[99] R. L. Davis, "Olfactory memory formation in Drosophila: from molecular to systems neuroscience," Annual Review of Neuroscience, vol. 28, pp. 275-302, 2005.

[100] Y. Fukazawa, Y. Saitoh, F. Ozawa, Y. Ohta, K. Mizuno, and K. Inokuchi, "Hippocampal LTP is accompanied by enhanced F-actin content within the dendritic spine that is essential for late LTP maintenance in vivo," Neuron, vol. 38, no. 3, pp. 447460, 2003.

[101] E. R. Kandel, "The molecular biology of memory storage: a dialogue between genes and synapses," Science, vol. 294, no. 5544, pp. 1030-1038, 2001.

[102] H. Watanabe, M. J. Smith, E. Heilig, V. Beglopoulos, R. J. Kelleher III, and J. Shen, "Indirect regulation of presenilins in CREB-mediated transcription," The Journal of Biological Chemistry, vol. 284, no. 20, pp. 13705-13713, 2009.

[103] B. J. Dickson, "Molecular mechanisms of axon guidance," Science, vol. 298, no. 5600, pp. 1959-1964, 2002.

[104] S. J. Araújo and G. Tear, "Axon guidance mechanisms and molecules: lessons from invertebrates," Nature Reviews Neuroscience, vol. 4, no. 11, pp. 910-922, 2003.

[105] T. E. Kennedy, "Cellular mechanisms of netrin function: long-range and short-range actions," Biochemistry and Cell Biology, vol. 78, no. 5, pp. 569-575, 2000.

[106] M. Yamagata, J. R. Sanes, and J. A. Weiner, "Synaptic adhesion molecules," Current Opinion in Cell Biology, vol. 15, no. 5, pp. 621-632, 2003.

[107] Y. Goda, "Cadherins communicate structural plasticity of presynaptic and postsynaptic terminals," Neuron, vol. 35, no. 1, pp. 1-3, 2002.

[108] M. Ozaki, "Neuregulins and the shaping of synapses," Neuroscientist, vol. 7, no. 2, pp. 146-154, 2001.

[109] Y. Yamaguchi and E. B. Pasquale, "Eph receptors in the adult brain," Current Opinion in Neurobiology, vol. 14, no. 3, pp. 288-296, 2004.

[110] Y. Takai, K. Shimizu, and T. Ohtsuka, "The roles of cadherins and nectins in interneuronal synapse formation," Current Opinion in Neurobiology, vol. 13, no. 5, pp. 520-526, 2003.

[111] P. Washbourne, A. Dityatev, P. Scheiffele et al., "Cell adhesion molecules in synapse formation," Journal of Neuroscience, vol. 24, no. 42, pp. 9244-9249, 2004.

[112] M. Leyssen, D. Ayaz, S. S. Hébert, S. Reeve, B. De Strooper, and B. A. Hassan, "Amyloid precursor protein promotes post-developmental neurite arborization in the Drosophila brain,” EMBO Journal, vol. 24, no. 16, pp. 2944-2955, 2005.

[113] C. Reinhard, S. S. Hébert, and B. De Strooper, "The amyloid$\beta$ precursor protein: integrating structure with biological function," EMBO Journal, vol. 24, no. 23, pp. 3996-4006, 2005.

[114] A. S. Yap and E. M. Kovacs, "Direct cadherin-activated cell signaling: a view from the plasma membrane," Journal of Cell Biology, vol. 160, no. 1, pp. 11-16, 2003.
[115] P. Marambaud, P. H. Wen, A. Dutt et al., "A CBP binding transcriptional repressor produced by the PS1/E-cleavage of $\mathrm{N}$-Cadherin is inhibited by PS1 FAD mutations," Cell, vol. 114, no. 5, pp. 635-645, 2003.

[116] P. Soba, S. Eggert, K. Wagner et al., "Homo- and heterodimerization of APP family members promotes intercellular adhesion," EMBO Journal, vol. 24, no. 20, pp. 36243634, 2005.

[117] J. L. Brusés, "N-cadherin signaling in synapse formation and neuronal physiology," Molecular Neurobiology, vol. 33, no. 3, pp. 237-252, 2006.

[118] A. Haapasalo, D. Y. Kim, B. W. Carey, M. K. Turunen, W. H. Pettingell, and D. M. Kovacs, "Presenilin $/ \gamma$-secretasemediated cleavage regulates association of Leukocytecommon Antigen-related (LAR) receptor tyrosine phosphatase with $\beta$-catenin," The Journal of Biological Chemistry, vol. 282, no. 12, pp. 9063-9072, 2007.

[119] M. A. Leissring, M. P. Murphy, T. R. Mead et al., "A physiologic signaling role for the $\gamma$-secretase-derived intracellular fragment of APP," Proceedings of the National Academy of Sciences of the United States of America, vol. 99, no. 7, pp. 4697-4702, 2002.

[120] P. Penzes, A. Beeser, J. Chernoff et al., "Rapid induction of dendritic spine morphogenesis by trans-synaptic ephrinBEphB receptor activation of the Rho-GEF kalirin," Neuron, vol. 37, no. 2, pp. 263-274, 2003.

[121] M. B. Dalva, M. A. Takasu, M. Z. Lin et al., "EphB receptors interact with NMDA receptors and regulate excitatory synapse formation," Cell, vol. 103, no. 6, pp. 945-956, 2000.

[122] M. Henkemeyer, O. S. Itkis, M. Ngo, P. W. Hickmott, and I. M. Ethell, "Multiple EphB receptor tyrosine kinases shape dendritic spines in the hippocampus," Journal of Cell Biology, vol. 163, no. 6, pp. 1313-1326, 2003.

[123] R. A. G. Garcia, K. Vasudevan, and A. Buonanno, "The neuregulin receptor ErbB-4 interacts with PDZ-containing proteins at neuronal synapses," Proceedings of the National Academy of Sciences of the United States of America, vol. 97, no. 7, pp. 3596-3601, 2000.

[124] J. A. Weiner, X. Wang, J. C. Tapia, and J. R. Sanes, "Gamma protocadherins are required for synaptic development in the spinal cord," Proceedings of the National Academy of Sciences of the United States of America, vol. 102, no. 1, pp. 8-14, 2005.

[125] A. W. Dunah, E. Hueske, M. Wyszynski et al., "LAR receptor protein tyrosine phosphatases in the development and maintenance of excitatory synapses," Nature Neuroscience, vol. 8, no. 4, pp. 458-467, 2005.

[126] R. Malinow and R. C. Malenka, "AMPA receptor trafficking and synaptic plasticity," Annual Review of Neuroscience, vol. 25, pp. 103-126, 2002.

[127] H. Kasai, M. Matsuzaki, J. Noguchi, N. Yasumatsu, and H. Nakahara, "Structure-stability-function relationships of dendritic spines," Trends in Neurosciences, vol. 26, no. 7, pp. 360-368, 2003.

[128] M. J. Galko and M. Tessier-Lavigne, "Function of an axonal chemoattractant modulated by metalloprotease activity," Science, vol. 289, no. 5483, pp. 1365-1367, 2000.

[129] Y. Taniguchi, S.-H. Kim, and S. S. Sisodia, "Presenilindependent " $\gamma$-secretase" processing of deleted in colorectal cancer (DCC)," The Journal of Biological Chemistry, vol. 278, no. 33, pp. 30425-30428, 2003.

[130] C. Hooper, R. Killick, and S. Lovestone, "The GSK3 hypothesis of Alzheimer's disease," Journal of Neurochemistry, vol. 104, no. 6, pp. 1433-1439, 2008. 
[131] A. Takashima, M. Murayama, O. Murayama et al., "Presenilin 1 associates with glycogen synthase kinase- $3 \beta$ and its substrate tau," Proceedings of the National Academy of Sciences of the United States of America, vol. 95, no. 16, pp. 9637-9641, 1998.

[132] Z. Zhang, H. Hartmann, V. M. Do et al., "Destabilization of $\beta$-catenin by mutations in presenilin-1 potentiates neuronal apoptosis," Nature, vol. 395, no. 6703, pp. 698-702, 1998.

[133] D. E. Kang, S. Soriano, X. Xia et al., "Presenilin couples the paired phosphorylation of $\beta$-catenin independent of axin: implications for $\beta$-catenin activation in tumorigenesis," Cell, vol. 110, no. 6, pp. 751-762, 2002.

[134] L. C. Cantley, "The phosphoinositide 3-kinase pathway," Science, vol. 296, no. 5573, pp. 1655-1657, 2002.

[135] T. Yoshimura, N. Arimura, and K. Kaibuchi, "Signaling networks in neuronal polarization," Journal of Neuroscience, vol. 26, no. 42, pp. 10626-10630, 2006.

[136] L.-Q. Zhu, S.-H. Wang, D. Liu et al., "Activation of glycogen synthase kinase-3 inhibits long-term potentiation with synapse-associated impairments," Journal of Neuroscience, vol. 27, no. 45, pp. 12211-12220, 2007.

[137] S. Peineau, C. Bradley, C. Taghibiglou et al., "The role of GSK-3 in synaptic plasticity," British Journal of Pharmacology, vol. 153, no. 1, pp. S428-S437, 2008.

[138] L. Baki, J. Shioi, P. Wen et al., "PS1 activates PI3K thus inhibiting GSK-3 activity and tau overphosphorylation: effects of FAD mutations," EMBO Journal, vol. 23, no. 13, pp. 2586-2596, 2004.

[139] G. Pigino, G. Morfini, A. Pelsman, M. P. Mattson, S. T. Brady, and J. Busciglio, "Alzheimer's presenilin 1 mutations impair kinesin-based axonal transport," Journal of Neuroscience, vol. 23, no. 11, pp. 4499-4508, 2003.

[140] L. Baki, R. L. Neve, Z. Shao, J. Shioi, A. Georgakopoulos, and N. K. Robakis, "Wild-type but not FAD mutant presenilin1 prevents neuronal degeneration by promoting phosphatidylinositol 3-kinase neuroprotective signaling," Journal of Neuroscience, vol. 28, no. 2, pp. 483-490, 2008.

[141] K. Tanemura, D.-H. Chui, T. Fukuda et al., "Formation of tau inclusions in knock-in mice with familial Alzheimer disease (FAD) mutation of presenilin 1 (PS1)," The Journal of Biological Chemistry, vol. 281, no. 8, pp. 5037-5041, 2006.

[142] D. E. Kang, I. S. Yoon, E. Repetto et al., "Presenilins mediate phosphatidylinositol 3-kinase/AKT and ERK activation via select signaling receptors: selectivity of PS2 in plateletderived growth factor signaling," The Journal of Biological Chemistry, vol. 280, no. 36, pp. 31537-31547, 2005.

[143] H. Cheng, K. S. Vetrivel, P. Gong, X. Meckler, A. Parent, and G. Thinakaran, "Mechanisms of disease: new therapeutic strategies for Alzheimer's disease-targeting APP processing in lipid rafts," Nature Clinical Practice Neurology, vol. 3, no. 7, pp. 374-382, 2007.

[144] H. Hering, C.-C. Lin, and M. Sheng, "Lipid rafts in the maintenance of synapses, dendritic spines, and surface AMPA receptor stability," Journal of Neuroscience, vol. 23, no. 8, pp. 3262-3271, 2003.

[145] T. Golub, S. Wacha, and P. Caroni, "Spatial and temporal control of signaling through lipid rafts," Current Opinion in Neurobiology, vol. 14, no. 5, pp. 542-550, 2004.

[146] L. Ma, Y. Z. Huang, G. M. Pitcher et al., "Ligand-dependent recruitment of the ErbB4 signaling complex into neuronal lipid rafts," Journal of Neuroscience, vol. 23, no. 8, pp. 3164 3175, 2003.
[147] Z. Hérincs, V. Corset, N. Cahuzac et al., "DCC association with lipid rafts is required for netrin-1-mediated axon guidance," Journal of Cell Science, vol. 118, no. 8, pp. 16871692, 2005.

[148] K. S. Vetrivel, H. Cheng, W. Lin et al., "Association of $\gamma$-secretase with lipid rafts in post-golgi and endosome membranes," The Journal of Biological Chemistry, vol. 279, no. 43, pp. 44945-44954, 2004.

[149] K. S. Vetrivel, H. Cheng, S.-H. Kim et al., "Spatial segregation of $\gamma$-secretase and substrates in distinct membrane domains," The Journal of Biological Chemistry, vol. 280, no. 27, pp. 25892-25900, 2005.

[150] G. E. Stutzmann, "The pathogenesis of Alzheimers diseaseis it a lifelong "calciumopathy"?" Neuroscientist, vol. 13, no. 5, pp. 546-559, 2007.

[151] F. M. LaFerla, "Calcium dyshomeostasis and intracellular signalling in Alzheimer's disease," Nature Reviews Neuroscience, vol. 3, no. 11, pp. 862-872, 2002.

[152] G. E. Stutzmann, A. Caccamo, F. M. LaFerla, and I. Parker, "Dysregulated IP3 signaling in cortical neurons of knock-in mice expressing an Alzheimer's-linked mutation in presenilin1 results in exaggerated $\mathrm{Ca}^{2+}$ signals and altered membrane excitability," Journal of Neuroscience, vol. 24, no. 2, pp. 508-513, 2004.

[153] Y. Lu, Y. Lv, Y. Ye et al., "A role for presenilin in post-stress regulation: effects of presenilin mutations on $\mathrm{Ca}^{2+}$ currents in Drosophila," FASEB Journal, vol. 21, no. 10, pp. 2368-2378, 2007.

[154] H. Tu, O. Nelson, A. Bezprozvanny et al., "Presenilins form ER $\mathrm{Ca}^{2+}$ leak channels, a function disrupted by familial Alzheimer's disease-linked mutations," Cell, vol. 126, no. 5, pp. 981-993, 2006.

[155] S. Chakroborty, I. Goussakov, M. B. Miller, and G. E. Stutzmann, "Deviant ryanodine receptor-mediated calcium release resets synaptic homeostasis in presymptomatic $3 \times \mathrm{Tg}$ AD mice," Journal of Neuroscience, vol. 29, no. 30, pp. 94589470, 2009. 


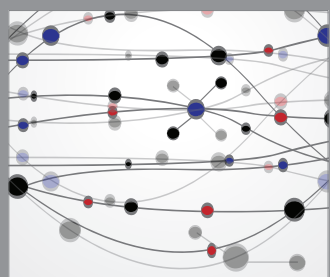

The Scientific World Journal
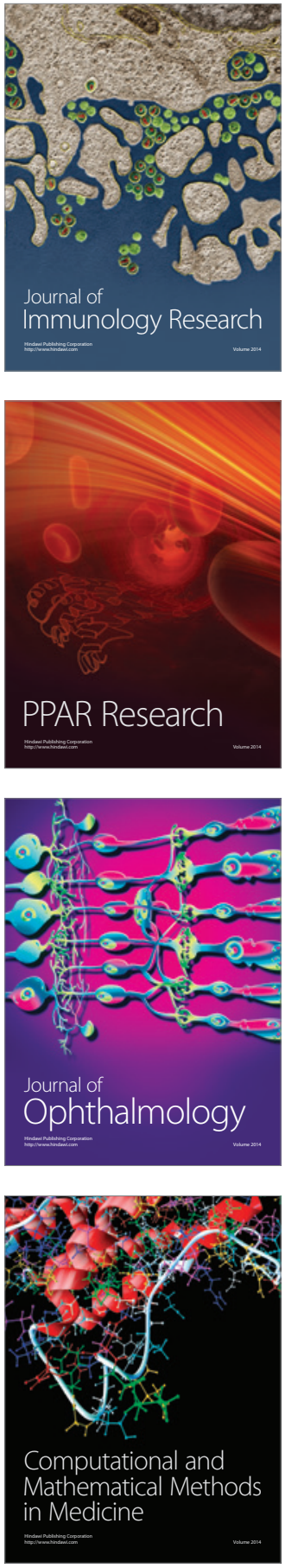

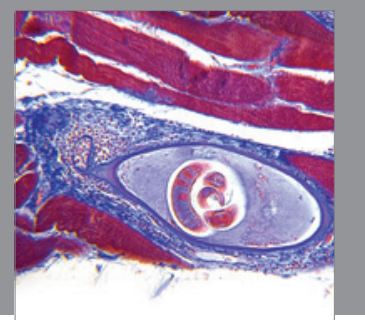

Gastroenterology

Research and Practice
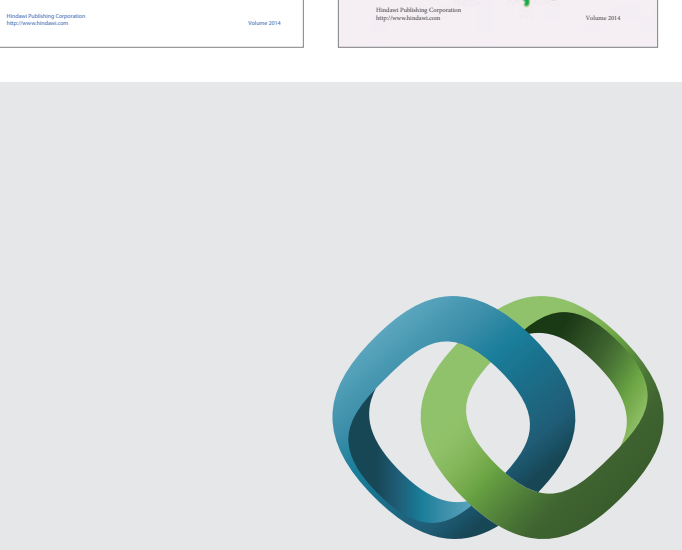

\section{Hindawi}

Submit your manuscripts at

http://www.hindawi.com
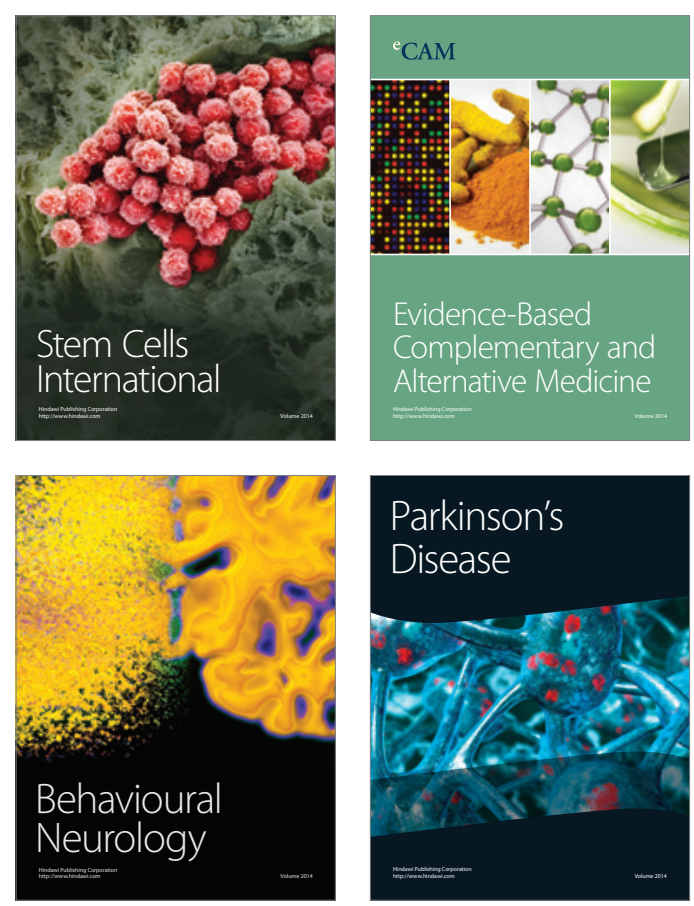

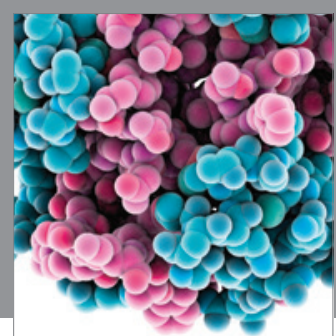

Journal of
Diabetes Research

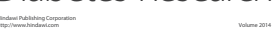

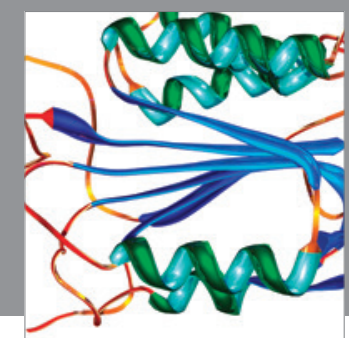

Disease Markers
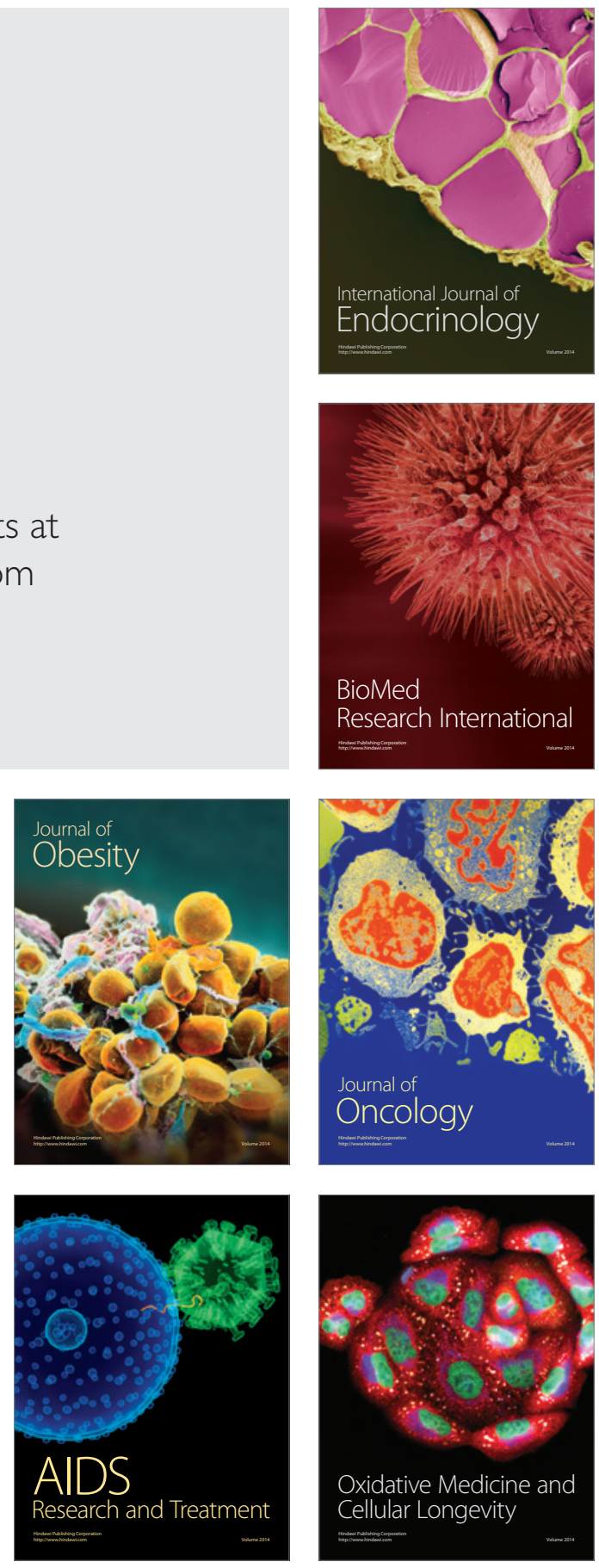